\title{
Denim Kumaşların Dikiş Performansları Üzerine Deneysel Bir Çalışma
}

\author{
Füsun DOBA KADEM*1 ${ }^{*}$, Gamze GÜLŞEN BAKICI² \\ ${ }^{1}$ Çukurova Üniversitesi, Mühendislik Mimarlık Fakültesi, Tekstil Mühendisliği Bölümü, Adana \\ ${ }^{2}$ Çukurova Üniversitesi, Teknik Bilimler Meslek Yüksekokulu, Tekstil-Giyim Bölümü, Adana
}

Geliş tarihi: 15.01.2016 Kabul tarihi: 22.03.2016

\section{Özet}

Bu çalışmada farklı konstrüksiyona sahip 4 denim kumaş, 110/18 numara dikiş iğnesi kullanılarak iki farklı dikiş ipliği ve iki farklı dikiş sıklığında standartlara uygun şekilde dikilmiş, dikiş mukavemeti testleri yapılmıştır. Aynı kumaşlara L\&M dikilebilirlik testi yapılmış ve sonuçlar kıyaslanmıştır. Kumaşları oluşturan iplik sıklıkları ve kalınlıkları arttıkça dikilebilirlik kuvveti (gf) artmakta ve kumaşın dikilebilirliği zorlaşmaktadır. Atkı ve çözgü yönlerinde dikiş sıklığı arttıkça dikiş mukavemeti artmaktadır. Numunelerin dikiş mukavemetleri kıyaslandığında; Gral dikiş ipliğinin mukavemeti Epic dikiş ipliğinin mukavemetinden daha yüksek olduğu için; Gral dikiş ipliği ile dikilen tüm numunelerin dikiş mukavemetleri, Epic dikiş ipliği ile dikilenlere nazaran daha yüksek çıkmıştır.

Anahtar Kelimeler: Denim, Dikilebilirlik, Dikiş mukavemeti, İğne batış kuvveti

\section{An Experimental Study About Seam Performance of Denim Fabrics}

\begin{abstract}
In this study, denim fabrics four different constructions were sewn with two different sewing thread and two different stitch densities per centimeter using sewing needle 110/18 number, seam strength tests were performed to the fabrics. L \& M sewability tests were performed to the same fabrics. Results of seam performance tests were compared with each other. When yarn thickness and density per centimeter increase, needle penetration force increase so sewability of fabrics is getting difficult. When stitch density per centimeter of fabrics in weft and warp directions increases, seam strength increases, too. When seam strength of the samples are compared; due to strength of the sewing thread Gral is higher than the sewing thread Epic seam strength of all samples sewn with the sewing thread Gral were higher than seam strength of the samples sewn with sewing thread Epic.
\end{abstract}

Keywords: Denim, Sewability, Seam strength, Needle penetration force

* Yazışmaların yapılacağı yazar: Füsun DOBA KADEM, Mühendislik Mimarlık Fakültesi, Tekstil Mühendisliği Bölümü, Adana, efsun72@cu.edu.tr 


\section{GíRiş}

Giysilerin kullanım ve görünüm kalitesini belirleyen en önemli faktör kumasının kalitesidir. Ancak kumaş kalitesi tek başına, yüksek kalitede giysiler üretmek için gerekli tüm kriterleri karşılayamaz. Giysi oluşturma aşamasında kaliteyi etkileyen başka faktörler de vardır ve bu faktörlerin en önemlilerinden biri dikiş kalitesidir. Giysileri oluşturan dikişler hem estetik hem de fonksiyonel açıdan yeterli olmalıdır [1]. Bir tekstil ürününden beklenen performans değeri, mamulün kullanım yerine bağlı olarak farklılık göstermektedir. Kullanım yerine göre istenen performans değerlerini elde edebilmek için; ürünün yapısal özellikleri, kullanılan hammadde ve uygulanan fiziksel yada kimyasal işlem gibi parametreler üzerinde Ar-Ge çalışmalarının yapılması gerekmektedir. Yapılacak bu çalışmaların değerlendirilmesi ve yeni tasarlanan bir ürünün son kullanım özelliklerinin tahmin edilebilmesi için de çeşitli kuvvetler karsısındaki davranışın ele alındığ 1 performans test ve analizlerin tekstil dokularına uygulanması gerekmektedir [2].

Dokuma kumaşlarda dikiş işlemi süresince iyi bir dikilebilirlik özelliği, dikiş iğnesinin kumaş içerisinden geçerken atkı ve çözgü ipliklerinin birbirinden ayrılması ve bu sayede dikişin kumaşa zarar vermeden gerçekleştirilmesi suretiyle elde edilebilir [3]. Dikiş mukavemeti, dikilmiş kumaşlarda dikiş yönüne dik olarak uygulanan bir kuvvet sonucunda dikiş yerlerinin kopmaya karşı gösterdiği dirençtir. Kopma uzaması da, dikişin koptuğu andaki \% uzama değeridir [4]. Dikiş, bir veya daha fazla dikiş sıraları ile iki veya daha fazla kumaşın birleştirilmesi anlamına gelmektedir. Enine gerilmeye maruz kaldığında, dikiş bölgesinde dikiş kayması meydana gelebilir. Bazı deneysel araştırmaların sonuçlarına göre dikiş açılması; kumaş yapısına, iplik sistemlerinin kumaş içerisindeki karakterlerine, dikiş tipine, dikiş sıklığına ve dikiş ipliği gerilimine bağlıdır [5]. Dikiş iğnesi batış kuvveti, dikiş prosesinin bir sonucu olarak meydana gelen zararın kantitatif olarak ölçümüdür [6].

\section{2. ÖNCEKİ ÇALIŞMALAR}

Pamuk/elastan karışımı dokuma kumaşlarda yapılan deneysel bir çalışmada dikiş mukavemeti, dikiş açılması, iğne penetrasyon kuvveti, iğne hasar indeksi değerleri tayin edilmiştir. Çalışmada fikse ve bitim işleminin kumaşların dikiş performansı, iğne penetrasyon kuvveti ve elastan lif hasarı üzerinde etkili olduğu, elastan çekim oranındaki farklılıkların ise etkili olmadığı, kumaşlara silikon uygulamasının dikiş performansını iyileştirdiği ve elastan lif hasarını önlediği sonucuna varılmıştır. [7].

Gömlek üretiminde yaygın olarak kullanılan aynı konstrüksiyona fakat farklı gramajlara sahip 3 dokuma kumaş ile 4 tür dokuma telanın dikilebilirliğinin araştırıldığı bir çalışmada L\&M Dikilebilirlik Test Cihazı kullanılarak farklı dokuma telalar ile işlem gören farklı dokuma kumaşların dikilebilirlik özellikleri incelenmiş, elde edilen bulgular iğne batış kuvveti, kumaş birim ağırlığı ve kumaş kalınlık değerleriyle ilişkilendirilmiştir. Kumaş birim ağırlığ kalınlığı arttıkça, kumaşın dikilebilirliğe karş1 gösterdiği direncin arttığ

Denim kumaşlarda seçilmiş bazı dikiş parametrelerinin dikiş mukavemetine etkisinin incelendiği deneysel bir çalışmada regresyon analizi ile üretim öncesi atkı ve çözgü dikiş mukavemetinin tahminlenmesi yapılmıştır [9].

Farklı konstrüksiyona sahip \%100 pamuklu denim kumaşların seçilmiş bazı fiziksel özelliklerinin kumaşın dikilebilirlik özelliği üzerindeki etkisinin L\&M Dikilebilirlik Test Cihazı ile tespit edildiği bir araştırmada, numunelerin iplik sıklıkları, gramajları ve kalınlıkları azaldıkça ve kumaşı oluşturan iplikler inceldikçe dikilebilirlik özelliğinin iyileştiği gözlenmiştir [10].

Farklı konstrüksiyona sahip $\% 100$ pamuklu dokuma kumaşların dikilebilirlik ve eğilme dayanımı özelliği üzerindeki etkisini araştıran bir çalışmanın sonucunda kumaşın örgü yapısının ve atkı sıklığının kumaşın dikilebilirlik özelliğini etkileyen parametreler olduğu ortaya konmuştur. 
Bezayağı, dimi (2/2) ve panama (2/2) olmak üzere üç farklı örgü yapısında, atkı ve çözgüde Ne 50 iplik numarasına sahip çözgü sıklığı $40 \mathrm{tel} / \mathrm{cm}$, üç farklı atkı sıklığında (26-30-34 tel/cm) pamuklu kumaşların dikilebilirliği incelenmiştir [11].

$\mathrm{Bu}$ çalışmada L\&M Dikilebilirlik Test Cihazı kullanılarak denim kumaşların iğne batış kuvvetleri gf cinsinden ölçülmüştür. Aynı kumaşların dikiş mukavemetleri de test edilmiş ve elde edilen sonuçlar yorumlanmıştır.

\section{MATERYAL VE METOT}

\subsection{Materyal}

Çalışmada kullanılan \%98 pamuk \%2 elastan içeren dört farklı konstrüksiyona sahip 3/1 Z dimi örgü yapısında denim kumaşların fiziksel özellikleri Çizelge 1'de verilmiştir.

Dikiş mukavemeti testleri için kumaşların birleştirilmesinde sonsuz elyaf polyester (ticari adı GRAL) ve polyester kapli polyester ilikli (ticari adı EPIC) olmak üzere iki farklı tipte dikiş ipliği kullanılmıştır. Alt ve üstü iplikler için ipliklerin numaraları değişmektedir. Kullanılan dikiş ipliklerinin özellikleri Çizelge 2'de [12] verilmiştir.

Çizelge 1. Denim kumaşların fiziksel özellikleri

\begin{tabular}{|c|c|c|c|c|c|}
\hline \multicolumn{2}{|c|}{ Numune } & $\begin{array}{c}\text { Siklık } \\
\text { (tel/cm) }\end{array}$ & $\begin{array}{c}\text { Numara } \\
(\mathrm{Nm})\end{array}$ & $\begin{array}{c}\text { Kalınlık } \\
(\mathrm{mm})\end{array}$ & $\begin{array}{c}\text { Gramaj } \\
\left(\mathrm{g} / \mathrm{m}^{2}\right)\end{array}$ \\
\hline \multirow{2}{*}{1} & Atk1 & 20 & 20 & \multirow{2}{*}{0,722} & \multirow{2}{*}{380} \\
\hline & Çözgü & 32 & 14 & & \\
\hline \multirow{2}{*}{2} & Atk1 & 20 & 24 & \multirow{2}{*}{0,64} & \multirow{2}{*}{317} \\
\hline & Çözgü & 32 & 16 & & \\
\hline \multirow{2}{*}{3} & Atk1 & 24 & 40 & \multirow{2}{*}{0,496} & \multirow{2}{*}{220} \\
\hline & Çözgü & 40 & 32 & & \\
\hline \multirow{2}{*}{4} & Atk1 & 24 & 42 & \multirow{2}{*}{0,488} & \multirow{2}{*}{200} \\
\hline & Çözgü & 40 & 34 & & \\
\hline
\end{tabular}

Kumaşların dikilebilirlik değerleri ve iğne batış kuvvetleri; Şekil 1'de görülen L\&M Dikilebilirlik Test Cihazı kullanılarak tayin edilmiştir. Bu cihaz, dikiş ipliği kullanılmadan dikiş iğnesinin kumaşa batışı için gereken kuvveti gf cinsinden ölçmektedir. En düşük eşik değeri 25 gf olup giysilik kumaşlar için bu değerin 150 gf'den fazla olmaması gerekmektedir [13].

Farklı konstrüksiyondaki her kumaş için $35 \mathrm{~mm} \times 350 \mathrm{~mm}$ ebatlarında 5'er adet atkı ve çözgü numuneleri hazırlanmıştır. Her numune üzerinde 2'şer ölçüm yapılabildiğinden 1 numune için atk1 ve çözgü yönündeki 10'ar adet ölçümün ortalaması alınmıştır. Çizelge 3'de dikilebilirlik testi için kullanılan test parametreleri verilmiştir. 


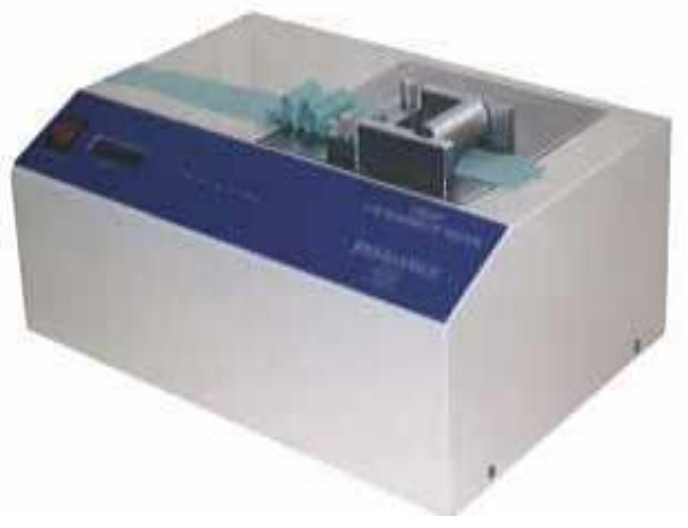

Şekil 1. L\&M dikilebilirlik test cihazı [13]

Çizelge 3. Dikilebilirlik test parametreleri

\begin{tabular}{|l|c|}
\hline Maksimum Kuvvet Aralığı (gf) & 500 \\
\hline İğne Batış Sayısı (adet) & 100 \\
\hline İğne Numarası & $110 / 18$ \\
\hline
\end{tabular}

\subsubsection{Dikiş Mukavemeti Testi}

TS 1619-2 EN ISO 13935-2 numaralı standarda göre test edilecek kumaşlar standarda [14] uygun kesildikten sonra iki farklı dikiş ipliği (düz dikiş) 301 dikişi ile birleştirilmiştir. Denim kumaş numunelerin $3 \mathrm{ad} ı \mathrm{~m} / \mathrm{cm}$ ve $3,5 \mathrm{ad} ı \mathrm{~m} / \mathrm{cm}$ dikiş sıklıklarında dikilmesi için $\mathrm{Nm}$ 110/18 numara dikiş iğnesi kullanılmıştır.

\section{BULGULAR VE DEĞERLENDIRME}

\subsection{Dikilebilirlik Testi Bulguları}

Çalışmada kullanılan dört farklı kumaşın iğne batış kuvvetleri ile iplik numaraları arasındaki ilişki Şekil 2'de gösterilmiştir.

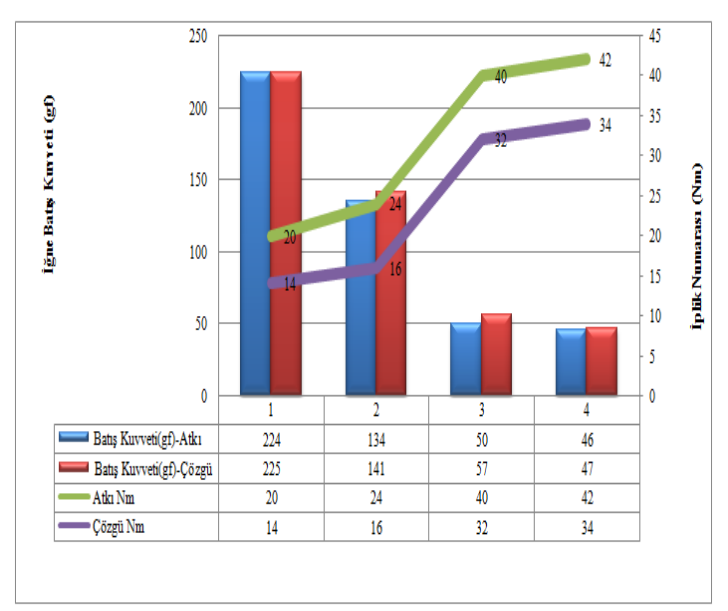

Şekil 2. İplik numaralarına göre dikilebilirlik test sonuçları

İğne batış kuvvetinin (gf) yükselmesi, kumaşın dikilebilirlik özelliğinin kötüleştiği anlamına gelmektedir. Şekilden de anlaşılacağı gibi 1 ile 2 nolu numunelerin 3 ile 4 nolu numunelerin iplik sıklıkları birbirleri ile aynıdır. $\mathrm{Bu}$ numunelerin iplik numaraları değişmektedir. İplik numaraları şekilde metrik sisteme göre verildiği için iplik numaraları arttıkça iplikler incelmekte ve iğne batış kuvvetleri (gf) azalmaktadır.

\subsection{Dikiş Mukavemeti}

Dikiş mukavemeti testleri için kumaşların birleştirilmesinde sonsuz elyaf polyester (ticari adı GRAL) ve polyester kapli polyester ilikli (ticari adı EPIC) olmak üzere iki farklı tipte dikiş ipliği kullanılmıştır. İki farklı dikiş ipliği ile iki farklı dikiş sıklığında dikilen numunelerin çözgü yönünde dikiş mukavemet değerleri Şekil 3'deki grafiklerde görülmektedir.

İki farklı dikiş sıklığında ve iki farklı dikiş ipliği kullanılarak dikilen numunelerin dikiş mukavemetleri kıyaslandığında; GRAL dikiş ipliğinin mukavemeti diğerinden daha yüksek olduğu için; GRAL dikiş ipliği ile dikilen tüm numunelerin dikiş mukavemetleri, EPIC ile dikilenlere nazaran daha yüksek çıkmıştır. Ayrıca 
numunelerin dikiş sıklığı arttıkça dikiş mukavemetleri de artmaktadır.

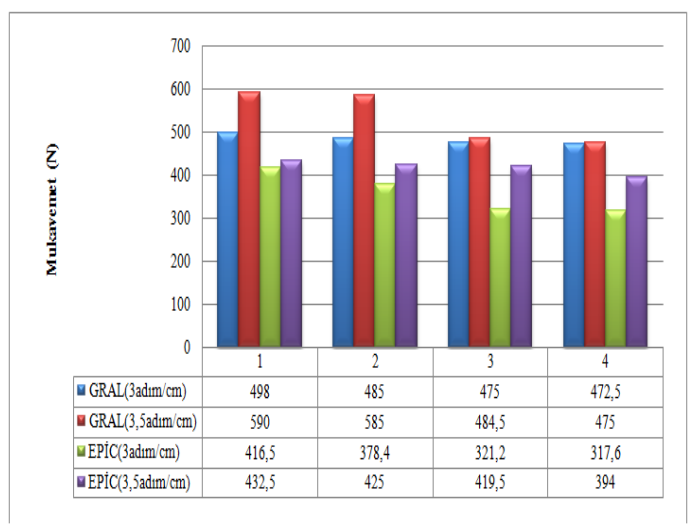

Şekil 3. Çözgü yönünde dikiş mukavemeti test sonuçları

Numunelerin atk1 yönünde dikiş mukavemet değerleri ise Şekil 4'deki grafiklerde görülmektedir.

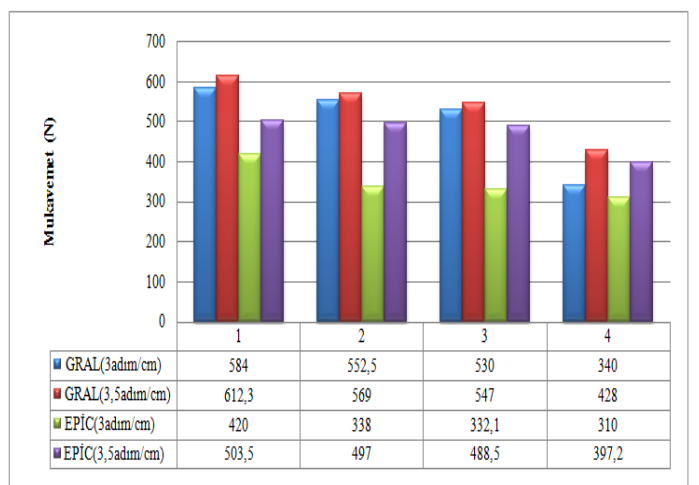

Şekil 4.Atkı Yönünde Dikiş Mukavemeti Test Sonuçları

Atkı yönünde dikiş mukavemet testi sonuçları çözgü yönündeki sonuçlara benzer çıkmıştır. Burada da dikiş sıklığı arttıkça numunelerin dikiş mukavemetlerinin de arttığ görülmektedir.

\section{SONUÇ}

Kumaşları oluşturan iplik sıklıkları ve kalınlıkları arttıkça dikilebilirlik kuvveti (gf) artmakta böylece kumaşın dikilebilirliği zorlaşmaktadır. Atkı ve çözgü yönlerinde dikiş sıklığının artmasıyla dikiş mukavemetinin arttığı söylenebilir. İki farklı dikiş sıklığında ve iki farklı dikiş ipliği kullanılarak dikilen numunelerin dikiş mukavemetleri kıyaslandığında; sonsuz elyaf polyester (GRAL) dikiş ipliğinin mukavemeti polyester kaplı polyester ilikli dikiş ipliğinden (EPIC) daha yüksek olduğu için GRAL dikiş ipliği ile dikilen tüm numunelerin dikiş mukavemetleri, EPIC ile dikilenlere nazaran daha yüksek çıkmıştır.

\section{KAYNAKLAR}

1. Bahar, S., 2006. Farklı Dikim ve Yıkama Türlerinin Dikim Performans Özelliklerine Etkisinin Araştırılması, Dokuz Eylül Üniversitesi, Fen Bilimleri Enstitüsü, Tekstil Mühendisliği Anabilim Dalı, Yüksek Lisans Tezi, İzmir,

2. Köstem, A.M., 2005. Farklı Buruşmazlık Apre Maddeleri Uygulanan Kumaşlarda Dikiş Performansının İncelenmesi, Uludağ Üniversitesi, Fen Bilimleri Enstitüsü, Tekstil Mühendisliği Anabilim Dalı, Yüksek Lisans Tezi, Bursa.

3. Manich, A.M., Domingues, J.P., Sauri, R.M., Barella, A., 1998. Relationships between fabric sewability and structural, physical, and FAST properties of woven wool and wool-blend fabrics, Journal of the Textile Institute, Vol. 89, Part 1, No. 3, pp.579-589.

4. Akgün Kuyucu, Y., 2009. Astarlık Kumaşlarda Dikiş Parametrelerinin Dikiş Mukavemetine Etkilerinin İncelenmesi, Marmara Üniversitesi, Fen Bilimleri Enstitüsü, Tekstil Eğitimi Anabilim Dalı, Yüksek Lisans Tezi, İstanbul.

5. Yıldırım, K., 2010. Predicting seam opening behavior of woven seat fabrics, Textile Research Journal doi: 10.1177/0040517509355348

6. Saied, F., Abdel-Megeid, Z.M., Gabry, L.K., 2011. The Relation Between Fabric Construction, Treatments and Sewability, Journal of American Science, Vol. 7, No. 3, pp. 818-826.

7. Gürarda A., Meriç, B., 2005. Sewing Needle Penetration Forces and Elastane Fiber Damage 
During the Sewing Of Cotton/Elastane Woven Fabrics, Textile Research Journal, Vol.75, No.8, 628-633.

8. Yıldız, E.Z., Pamuk, O., Öndoğan, Z., 2011. A Study about the Effects of Interlinings to Sewability Properties of the Woven Fabrics. Tekstil ve Konfeksiyon, 1, pp. 87-90.

9. Zervent Ünal, B., 2012. The Prediction of Seam Strength of Denim Fabrics with Mathematical Equations. The Journal of the Textile Institute, 103 ( 7), pp. 744-751.

10. Gülşen G., Doba Kadem F., 2014. Farklı Konstrüksiyonlu Denim Kumaşlarda Dikilebilirlik Üzerine bir Araştırma, 2.Uluslararası Tekstil Zirvesi (UTZ 2014), Kahramanmaraş.

11. Gülşen Bakıcı G., Doba Kadem F., 2015. An Experimental Study about Sewability and Bending Strength Properties of Cotton Fabrics, Çukurova Üniversitesi Mühendislik-Mimarlık Fakültesi Dergisi,Cilt 30, Sayı 2, 177-172.

12. https://www.coatsindustrial.com/tr

13. The L\&M Sewability Tester Catalogue

14. TS 1619-2 EN ISO 13935-2: 2002. TekstilKumaş ve Hazır Giyim Ürünlerinin Dikiş Gerilme Özellikleri-Bölüm 2: En Büyük Dikiş Kopma Kuvvetinin Tayini-Kavrama Metodu, Türk Standartları Enstitüsü, Ankara. 